\title{
Évolution et rôle des congrégations religieuses enseignantes féminines au Québec, 1840-1960
}

\section{Micheline Dumont et Marie-Paule Malouin}

Volume 50, numéro 1, 1983

Bilan de l'histoire religieuse au Canada

Canadian Catholic History: A survey

URI : https://id.erudit.org/iderudit/1007044ar

DOI : https://doi.org/10.7202/1007044ar

Aller au sommaire du numéro

Éditeur(s)

Les Éditions Historia Ecclesiæ Catholicæ Canadensis Inc.

ISSN

0318-6172 (imprimé)

1927-7067 (numérique)

Découvrir la revue

Citer cet article

Dumont, M. \& Malouin, M.-P. (1983). Évolution et rôle des congrégations religieuses enseignantes féminines au Québec, 1840-1960. Sessions d'étude -

Société canadienne d'histoire de l'Église catholique, 50(1), 201-230.

https://doi.org/10.7202/1007044ar

Tous droits réservés @ Les Éditions Historia Ecclesiæ Catholicæ Canadensis Inc., 1983
Ce document est protégé par la loi sur le droit d'auteur. L'utilisation des services d'Érudit (y compris la reproduction) est assujettie à sa politique d'utilisation que vous pouvez consulter en ligne. 


\section{Évolution et rôle des congrégations religieuses enseignantes féminines au Québec, 1840-1960}

Depuis 1981, un collectif de recherches s'est constitué à Montréal. Il comprend une équipe de douze personnes sous la direction de Nadia Eid (UQAM) et Micheline Dumont (Sherbrooke) avec le concours d'une assistante senior, Marie-Paule Malouin (Montréal) et d'une dizaine d'étudiantes-assistantes. Son objectif: explorer la question de l'histoire de l'éducation des filles au Québec. Ce champ de recherches était, il y a cinq ans, à peine exploré: en fait, les quelques monographies pertinentes sur la question datent de 1980, si on excepte les thèses inédites ${ }^{1}$.

Avec l'enthousiasme et la détermination des pionnières, nous avons donc décidé de défricher les archives. Nous avons vite été confrontées à de redoutables problèmes. Les chiffres officiels nous apprenaient que c'est au niveau primaire que l'on retrouve la très grande majorité des filles. Mais les documents publics sont avares de renseignements sur l'instruction des filles à ce niveau ${ }^{2}$. Toutefois, l'examen, même superficiel des structures éducatives (personnel enseignant, types d'écoles, autorités scolaires) nous apprenait ce qu'au fond nous savions déjà par expérience: le rôle central des congrégations religieuses dans l'éducation des filles. Il était donc logique d'explorer leurs archives. Mais vous devinez notre désarroi: tant de congrégations! des archives couvrant de si longues périodes! des archives parfois difficile à consulter! tant de recoupements à établir entre les diverses congrégations!

\footnotetext{
${ }^{1}$ Pour un bilan de la recherche sur cette question voir: Nadia Fahmy-Eid et Micheline Dumont, Mâ̂tresses de maison, Maîtresses d'école. Le rapport femmesfamille-éducation dans l'histoire du Québec, Montréal, Boréal-Express, 1983, 415 p. Voir surtout pp. 25-46.

${ }^{2}$ Ce phénomène est général dans tout le monde occidental et a été observé par toutes les historiennes de l'éducation des filles. Voir note précédente.
} 
À date, treize monographies ont été préparées sur autant de congrégations distinctes ${ }^{3}$. Cinq autres sont en cours de rédaction sur des questions globales se retrouvant dans plusieurs congrégations. De sorte que d'ores et déjà nous pouvons identifier plusieurs séries de questions qui permettent d'appréhender globalement l'évolution des congrégations enseignantes de femmes. Et rassurons les adversaires de l'histoire des élites: nous avons trouvé autant de documentation sur le niveau primaire que sur les autres niveaux d'enseignement. Marie-Paule Malouin a consacré une thèse de maîtrise à l'Académie Marie-Rose, pensionnat "respecté» des Soeurs de Jésus-Marie (mais pas le plus huppé). Sa thèse est, à ce jour, l'étude la plus éclairante sur l'enseignement public à Montréal au XIX ${ }^{\mathrm{e}}$ siècle ${ }^{4}$.

Parmi toutes les questions que nous aurions pu aborder, nous avons choisi de vous en présenter deux: une brève description de l'évolution des effectifs des congrégations entre 1840 et 1960 , en tentant d'illustrer les traits les plus significatifs de cette évolution; une analyse du rôle des congrégations face à l'établissement des programmes d'études destinés aux filles et du développement de l'enseignement «secondaire» plus généralisé. En conclusion, nous voulons mettre en relief quelques ambiguités qui semblent caractériser les entreprises des congrégations religieuses.

\section{DESCRIPTION QUANTITATIVE DE L'ÉVOLUTION}

Lorsque s'instaure le premier véritable réseau d'enseignement public au Bas-Canada en 1840, il y a peu de congrégations enseignantes: seules les Ursulines et les Dames de la Congrégation sont à l'oeuvre, reproduisant ici les deux modèles français: l'enseignement réservé à une élite (avec classes pour les pauvres): c'est le modèle des Ursulines; l'enseignement destiné à une clientèle plus modeste et plus nombreuse, enseignement rendu accessible par un petit réseau de pensionnats ${ }^{5}$ :

\footnotetext{
${ }^{3}$ Un bilan provisoire de cette recherche doit paraître dans Resources for Feminist Research/Documentation sur la recherche féminine, vol. XII, no. 3 (automne 1983).

${ }^{4}$ Voir Marie-Paule Malouin, «Les rapports entre l'école privée et l'école publique: l'Académie Marie-Rose au $19^{e}$ siècle» dans Maîtresses de maison, Maîtresses d'école, pp. 77-92.

${ }^{5}$ Les termes pensionnat et couvent sont utilisés indifféremment dans le langage courant. Pourtant, chaque mot désigne une réalité distincte: le pensionnat est une école/ internat qui accueille parfois des externes appelées «quart-de-pension». Le couvent est la maison où habitent les religieuses.
} 
c'est le modèle de la Congrégation Notre-Dame (C.N.D.). En 1800, les Ursulines possèdent deux pensionnats et la Congrégation en a douze, la plupart créés sous le régime français: elle en ouvre huit de 1800 à $1841^{6}$. Il y a donc 22 pensionnats dans le Bas-Canada vers 1840 . En 1960, 67 congrégations dirigent 1799 maisons diverses reliées à l'éducation ${ }^{7}$. Cet essor mérite qu'on s'y arrête.

Le premier phénomène est certainement le foisonnement des congrégations. Dix congrégations enseignantes sont fondées au Québec entre 1843 et 1894 et deux autres au $\mathrm{XX}^{\mathrm{e}}$ siècle (Tableau 1$)^{8}$.

TABLEAU 1. Congrégations religieuses enseignantes fondées au Québec

1. 1653 Congrégation de Notre-Dame

2. 1843 Soeurs des Saints Noms de Jésus et de Marie

3. 1849 Soeurs de la Charité de Québec

4. 1850 Soeurs de Sainte-Anne

5. 1850 Servantes du Coeur-Immaculée-de-Marie

6. 1853 Soeurs de l'Assomption de la Sainte-Vierge

7. 1874 Soeurs de Notre-Dame du Saint-Rosaire

8. 1877 Soeurs de Saint-Joseph de Saint-Hyacinthe

9. 1891 Petites Franciscaines de Marie

10. 1892 Soeurs de Notre-Dame du Perpétuel-Secours

11. 1894 Soeurs de Notre-Dame du Bon Conseil de Chicoutimi

12. 1921 Soeurs de Notre-Dame auxiliatrice

13. 1950 Société des Soeurs des Saints-Apôtres

SOURCE: Bernard Denault, "Sociographie générale des communautés religieuses au Québec (1837-1970)» dans Éléments pour une sociologie des communautés religieuses au Québec, Montréal, PUM, 1975, Annexe II *Liste alphabétique des communautés religieuses du Québec», p. 197-201.

\footnotetext{
${ }^{6}$ Voir Marguerite Jean, Evolution des communautés religieuses de femmes au Canada de 1639 à nos jours, Montréal, Fides, 1977. Histoire de la congrégation de Notre-Dame de Montréal, Montréal, vol. VI, VII et VIII, passim.

${ }^{7}$ Le Canada ecclésiastique, 1960. Voir Tableau 10.

${ }^{8}$ Marguerite Jean, Évolution, passim.
} 
De plus, plusieurs autres congrégations québécoises à vocation charitable, hospitalière ou missionnaire développent parallèlement à leur oeuvre un réseau de maisons d'éducation et l'on peut penser que cette initiative, accessoire à l'oeuvre principale, a pour objectif le recrutement des vocations religieuses. Les Soeurs de la Providence, les Soeurs Grises de Montréal et les Soeurs Missionnaires de l'Immaculée-Conception sont de bons exemples de ce phénomène. Seuls les ordres contemplatifs et les congrégations vouées au service domestique du clergé n'ont pas recours à cette stratégie.

Par ailleurs, le Québec, on le sait, est le lieu d'implantation d'un plus grand nombre encore de congrégations religieuses venues d'Europe, de France principalement (Tableau 2). Or, les religieuses enseignantes constituent la majorité de cette immigration.

TABLEAU 2. Nombre de congrégations enseignantes féminines francophones implantées au Québec de 1840 à 1960

\begin{tabular}{|cc|}
\hline $1840-1859$ & 5 congrégations \\
$1860-1879$ & 1 congrégation \\
$1880-1899$ & 3 congrégations \\
$1900-1919$ & 13 congrégations \\
$1920-1939$ & 4 congrégations \\
$1940-1960$ & 18 congrégations \\
TOTAL & 44 congrégations \\
\hline
\end{tabular}

SOURCE: Bernard Denault, ibid.

Ces chiffres impressionnants doivent être éclairés. Les dernières venues de ces congrégations ne comptent certes pas de nombreuses maisons; de plus leur personnel est très réduit. Mais il n'en est pas de même pour la majorité des congrégations implantées au Québec avant 1920: la plupart ont connu un développement similaire à celui des fondations québécoises. En fait, on peut distinguer deux modèles dans cet ensemble; les grandes congrégations qui sont surtout les fondations québécoises; les petites congrégations, qui sont surtout des implantations françaises. En 1969, avec moins du quart des congré- 
gations enseignantes, les congrégations fondées au Québec comptaient $60 \%$ de toutes les religieuses enseignantes (Tableau 3 ).

TABLEAU 3. Nombre de sujets des congrégations enseignantes féminine au Québec en 1969

(francophones seulement)

\begin{tabular}{|l|c|c|}
\hline \multicolumn{1}{|c|}{ Congrégations } & $\begin{array}{c}\text { Fondées au } \\
\text { Québec }\end{array}$ & $\begin{array}{c}\text { Implantées } \\
\text { au Québéc }\end{array}$ \\
\hline de 2,000 sujets et plus & 3 & 1 \\
\hline de 800 à 2,000 sujets & 5 & 3 \\
\hline 100 à 799 sujets & 4 & 16 \\
\hline 40 à 99 sujets & - & 6 \\
\hline 39 sujets et moins & 1 & 19 \\
\hline TOTAL & 13 & 45 \\
& $(22,5 \%)$ & $(77,5 \%)$ \\
\hline
\end{tabular}

SOURCE : Bernard Denault, ibid.

Le second phénomène à souligner est l'importance et la dispersion du réseau d'écoles/pensionnats qui a résulté de cet ensemble de fondations. Il sera également intéressant d'évaluer cette importance et cette dispersion en examinant le rythme de sa progression et la place des principales congrégations dans le tableau d'ensemble. Cela sera possible grâce à une recherche systématique dans sept annuaires du Canada ecclésiastique, allant de 1887 à 1917.

Nous présentons ici quelques résultats de cette recherche avec prudence. Le Canada ecclésiastique, on le sait, ne fournit pas toujours des données sûres. Toutefois la période de trente ans que nous avons choisie offre une grande homogénéité dans ses statistiques et fournit, sinon des chiffres exacts, au moins un ordre de grandeur ou des proportions qui permettent d'atteindre notre but d'examiner la progression des congrégations religieuses dans les réseaux public et privé d'enseignement. Une recherche spécialisée ${ }^{9}$ sur les congrégations religieuses

\footnotetext{
${ }^{9}$ Jacques Desgrandchamps, Monseigneur Antoine Racine et les communautés de religieuses enseignantes, Sherbrooke, Groupe de recherche en histoire des Cantons de l'Est, 1980, passim.
} 
enseignantes du diocèse de Sherbrooke au XIX ${ }^{\mathrm{e}}$ siècle permet de penser que les chiffres du Canada ecclésiastique sont inférieurs à ceux de la clientèle totale qui fréquente les écoles/pensionnats.

Les 22 couvents de 1841 ont servi de modèles à des dizaines d'autres pendant qu'un grand nombre d'écoles publiques sont confiées aux religieuses. Le tableau 4 nous en donne une idée.

TABLEAU 4. Progression des congrégations enseignantes féminines au Québec de 1887 à 1917

\begin{tabular}{|l|c|c|r|c|}
\hline Année & \multicolumn{2}{|c|}{ Nombre d'institutions } & \multicolumn{2}{c|}{ Nombre d'élèves } \\
\hline & Nombre & $\%$ d'augmentation & Nombre & $\%$ d'augmentation \\
\hline 1887 & 194 & -- & 37157 & -- \\
\hline 1892 & 233 & $20 \%$ & 47281 & $27 \%$ \\
\hline 1897 & 265 & $13,5 \%$ & 55571 & $17,5 \%$ \\
\hline 1902 & 301 & $13,5 \%$ & 65018 & $17 \%$ \\
\hline 1907 & 368 & $22 \%$ & 75294 & $16 \%$ \\
\hline 1912 & 431 & $17 \%$ & 95684 & $27 \%$ \\
\hline 1917 & 492 & $14 \%$ & 127801 & $33,5 \%$ \\
\hline $\begin{array}{l}\text { Augmen- } \\
\text { tation } \\
\text { totale }\end{array}$ & & $153 \%$ & & $243 \%$ \\
\hline
\end{tabular}

SOURCE: Le Canada ecclésiastique, 1887, 1892, 1897, 1902, 1907, 1912, 1917.

Le nombre d'institutions dirigées par les religieuses fait plus que doubler en une seule génération. Le nombre d'élèves lui augmente de $243 \%$ et son rythme d'accroissement est beaucoup plus rapide que celui des institutions. Nous sommes manifestement en face d'un mouvement d'expansion irrésistible. Ce mouvement, on le verra, s'est maintenu jusqu'à la révolution tranquille.

Il est intéressant de noter également la performance des principales congrégations enseignantes (Tableau 5) ${ }^{10}$. La Congrégation Notre-Dame,

${ }^{10}$ Cette importance a été établie à partir du nombre de sujets de chaque congrégation en 1969, telle qu'établie dans l'annexe de Bernard Denault. Une erreur technique est responsable de l'absence des Servantes du Coeur-Immaculée-de-Marie dans les tableaux 5,6 et 8. 
forte de sa longue tradition et de sa présence dans tous les diocèses (sa fondation est antérieure à la création de nouveaux diocèses), est de loin la congrégation la plus active. Toutefois, son rythme de croissance est beaucoup plus lent. Par comparaison, l'essor des Soeurs des SaintsNoms-de-Jésus-et-Marie est spectaculaire de même que celui des petites Soeurs du Saint-Rosaire, vouées à l'enseignement dans les milieux ruraux.

TABLEAU 5. Progression des principales congrégations enseignantes féminines au Québec

\begin{tabular}{|l|c|c|c|}
\hline Congrégations & \multicolumn{3}{|c|}{ Nombre d'institutions } \\
\hline $\begin{array}{c}\text { Congrégation de Notre-Dame } \\
(1653)\end{array}$ & 1887 & 1917 \% d'augmentation \\
\hline $\begin{array}{c}\text { Soeurs des Saints Noms de J.M. } \\
(1843)\end{array}$ & 16 & 56 & $52 \%$ \\
\hline $\begin{array}{c}\text { Soeurs de Ste-Croix } \\
(1847)\end{array}$ & 11 & 26 & $136 \%$ \\
\hline $\begin{array}{c}\text { Soeurs de la Charité de Québec } \\
(1849)\end{array}$ & 16 & 30 & $88 \%$ \\
\hline $\begin{array}{c}\text { Soeurs de Ste-Anne } \\
(1850)\end{array}$ & 19 & 35 & $84 \%$ \\
\hline $\begin{array}{c}\text { Soeurs de l'Assomption } \\
(1853)\end{array}$ & 15 & 35 & $133 \%$ \\
\hline $\begin{array}{c}\text { Soeurs de la Présentation } \\
(1853)\end{array}$ & $19(1892)^{1}$ & 29 & $52 \%$ \\
\hline $\begin{array}{c}\text { Soeurs du St-Rosaire } \\
(1874)\end{array}$ & 6 & 27 & $350 \%$ \\
\hline Autres congrégations & 53 & 166 & $213 \%$ \\
\hline TOTAL & 194 & 492 & $153 \%$ \\
\hline
\end{tabular}

(1) Le chiffre de 1887 n'est pas disponible.

SOURCE : Le Canada ecclésiastique, 1887, 1917.

La répartition par diocèses est également intéressante à observer. Elle s'explique bien sûr par le lieu de la fondation ou de l'implantation mais également par la date de fondation. Les subdivisions de diocèses, en effet, augmentent les occasions d'expansion: dans cette 
recherche de "marchés", les pllıs anciennes congrégations se trouvent toujours favorisées. Il semble par ailleurs qu'évêques et supérieures aient tenu à éviter les concurrences trop vives en tentant de se répartir équitablement les clientèles ${ }^{11}$. Le tableau 6 , toutefois, laisse croire qu'on pouvait se bousculer dans certains diocèses.

TABLEAU 6. Répartition des principales congrégations enseignantes féminines dans les diocèses du Québec en 1917

\begin{tabular}{|c|c|c|c|c|c|c|c|c|c|c|c|}
\hline Congrégatons & 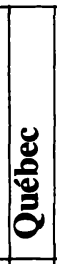 & 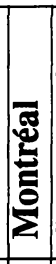 & 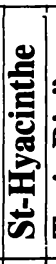 & 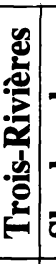 & 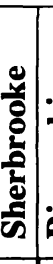 & 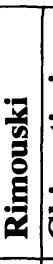 & : & & 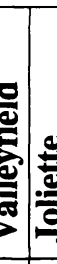 & & : \\
\hline Congrégation Notre-Dame & $\square$ & $\square$ & $\square$ & ㅁ. & $\square$ & & 맘 & $\square$ & $\square$ & $\square$ & \\
\hline Saints Noms de Jésus-Marie & & $\square$ & $\square$ & & $\square$ & & 口 & $\square$ & $\square$ & & \\
\hline Charité de Québec & $\square$ & & & & & $\square$ & 口 & & & & \\
\hline Sainte-Croix & & ㅁ. & & & 口 & & & & & 口 & \\
\hline Sainte-Anne & & ㅁ & & & & & & & $\square$ & $\square$ & \\
\hline Assomption & & & & 만다 & $\square$ & & & 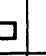 & & & \\
\hline Présentation de Marie & & & 口 & & $\square$ & & & 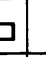 & & & \\
\hline Saint-Rosaire & & & & & & $\square$ & $\square$ & & & & \\
\hline $\begin{array}{l}\text { Nombre total de congrégations } \\
\text { enseignantes féminines } \\
\text { dans le diocèse }\end{array}$ & 13 & 9 & 5 & 4 & 6 & 7 & 6 & 43 & & 5 & 2 \\
\hline
\end{tabular}

SOURCE : Le Canada ecclésiastique, 1917.

Ce partage des diocèses laisse prévoir une importante constatation: que les religieuses sont également répandues dans tous les milieux de vie. Nous avons divisé le territoire québécois, en quatre zones: Montréal et Québec, qui représentent le milieu urbain; les petites villes de 3000 habitants et plus; les villages situés dans un rayon périphérique des agglomérations urbaines; les villages éloignés. Cette répartition s'est faite avec les chiffres de population de la fin du XIX ${ }^{e}$ siècle. Le tableau 7 illustre cette répartition pour les deux extrémités de la période analysée.

\footnotetext{
${ }^{11}$ Cette affirmation repose sur les travaux de notre équipe de recherches.
} 
TABLEAU 7. Répartition des congrégations religieuses selon le milieu de vie de leurs élèves en 1887 et $1917: \%$ des élèves

\begin{tabular}{|l|c|c|}
\hline & 1887 & 1917 \\
\hline Montréal et Québec & $28 \%$ & $34 \%$ \\
\hline Petites villes & $20 \%$ & $13 \%$ \\
\hline Villages périphériques & $27 \%$ & $19 \%$ \\
\hline Villages éloignés & $25 \%$ & $34 \%$ \\
\hline & $100 \%$ & $100 \%$ \\
\hline
\end{tabular}

SOURCE: Le Canada ecclésiastique, 1887, 1917.

En fait, en 1887, les quatre milieux sont presqu'également touchés par le travail des religieuses enseignantes tandis qu'en 1917, on note une augmentation des élèves des soeurs dans les grandes villes et les villages éloignés.

Mais ce tableau dissimule le visage de chaque congrégation. Le tableau 8 permet de distinguer quelques modèles. Deux congrégations sont plus concentrées dans les grandes villes, spécialement en 1917: les Soeurs des Saints-Noms-de-Jésus-et-Marie et les Soeurs de Ste-Croix. Trois autres congrégations sont plus également réparties entre les milieux: la congrégation Notre-Dame, les Soeurs de Ste-Anne et les Soeurs de la Charité de Québec. Les Soeurs de l'Assomption se retrouvent toutes dans des villages et les Soeurs de la Présentation, présentes dans plusieurs villes, sont absentes des grandes villes. Quant aux Soeurs du St-Rosaire, on ne les trouve que dans les villages éloignés. Ces chiffres infirment quelque peu une croyance impressionniste qui prétend que les religieuses n'ont enseigné que dans les milieux urbains. 
TABLEAU 8. Répartition géographique de quelques congrégations religieuses enseignantes en 1887 et 1917 (\% des élèves)

\begin{tabular}{|l|c|c|c|c|c|c|c|c|}
\hline & \multicolumn{2}{|c|}{$\begin{array}{c}\text { Montréal } \\
\text { et Québec }\end{array}$} & \multicolumn{2}{c|}{$\begin{array}{c}\text { Petites } \\
\text { villes }\end{array}$} & \multicolumn{2}{|c|}{$\begin{array}{c}\text { Villages } \\
\text { périphé- } \\
\text { riques }\end{array}$} & \multicolumn{2}{c|}{$\begin{array}{c}\text { Villages } \\
\text { éloignés }\end{array}$} \\
\hline & $\mathbf{1 8 8 7}$ & $\mathbf{1 9 1 7}$ & $\mathbf{1 8 8 7}$ & $\mathbf{1 9 1 7}$ & $\mathbf{1 8 8 7}$ & $\mathbf{1 9 1 7}$ & $\mathbf{1 8 8 7}$ & $\mathbf{1 9 1 7}$ \\
\hline $\begin{array}{l}\text { Congrégation } \\
\text { Notre-Dame }\end{array}$ & $49 \%$ & $51 \%$ & $12 \%$ & $15 \%$ & $18 \%$ & $15 \%$ & $21 \%$ & $18 \%$ \\
\hline $\begin{array}{l}\text { Saints-Noms-de- } \\
\text { Jésus-Marie }\end{array}$ & $28 \%$ & $65 \%$ & $23 \%$ & $9 \%$ & $36 \%$ & $20 \%$ & $13 \%$ & $6 \%$ \\
\hline Sainte-Croix & $47 \%$ & $80 \%$ & $21 \%$ & $6 \%$ & $32 \%$ & $11 \%$ & $0 \%$ & $3 \%$ \\
\hline Sainte-Anne & $34 \%$ & $55 \%$ & $9 \%$ & $5 \%$ & $43 \%$ & $30 \%$ & $14 \%$ & $10 \%$ \\
\hline Charité de Québec & $18 \%$ & $28 \%$ & $20 \%$ & $12 \%$ & $22 \%$ & $14 \%$ & $40 \%$ & $46 \%$ \\
\hline Assomption & - & - & - & - & $72 \%$ & $35 \%$ & $28 \%$ & $65 \%$ \\
\hline $\begin{array}{c}\text { Présentation de } \\
\text { Marie (1892) }\end{array}$ & - & - & $30 \%$ & $26 \%$ & $6 \%$ & $13 \%$ & $64 \%$ & $61 \%$ \\
\hline Saint-Rosaire & - & - & - & - & - & - & $100 \%$ & $100 \%$ \\
\hline
\end{tabular}

SOURCE: Le Canada ecclésiastique, 1887, 1917.

Cet essor remarquable doit cependant être pondéré en situant le groupe des religieuses enseignantes dans l'ensemble du personnel enseignant. Cette entreprise pose des problèmes méthodologiques considérables qu'il serait trop long d'exposer ici ${ }^{12}$. Le tableau 9 éclaire quelque peu ce truisme de l'histoire de l'éducation au Québec, à savoir que religieux et religieuses ont pénétré l'enseignement dès le milieu du $19^{\mathrm{e}}$ siècle et l'on dominé durant la première moitié du $\mathrm{XX}^{\mathrm{e}}$ siècle.

\footnotetext{
${ }^{12}$ Signalons le plus important: les Rapports du Surintendant de l'instruction publique n'identifient pas tous les réseaux d'enseignement dans les pourcentages du personnel enseignant, puisqu'il ne comptabilise que le personnel des écoles sous contrôle.
} 
TABLEAU 9. Proportion des religieuses enseignantes dans l'ensemble du personnel enseignant de la province de Québec, en $1874,1888,1900,1940,1960$

(Écoles sous contrôle et indépendantes)

\begin{tabular}{|c|c|c|c|c|c|}
\hline Date & Instituteurs & Religieux & Institutrices & Religieuses & Total \\
\hline 1874 & $\begin{array}{c}646 * \\
(11 \%)\end{array}$ & $\begin{array}{c}435 \\
(7.5 \%)\end{array}$ & $\begin{array}{c}3866 * \\
(67 \%)\end{array}$ & $\begin{array}{c}840 \\
(14.5 \%)\end{array}$ & $\begin{array}{c}5787 \\
(100 \%)\end{array}$ \\
\hline 1888 & $\begin{array}{c}287 \\
(4 \%)\end{array}$ & $\begin{array}{c}912 \\
(13 \%)\end{array}$ & $\begin{array}{c}3875 \\
56.5 \%)\end{array}$ & $\begin{array}{c}1804 \\
(26.5 \%)\end{array}$ & $\begin{array}{c}6878 \\
(100 \%)\end{array}$ \\
\hline 1900 & $2.3 \%$ & $10.2 \% * *$ & $55 \%$ & $32.5 \% * *$ & $100 \%$ \\
\hline 1940 & $6.6 \%$ & $13.5 \%$ & $44.2 \%$ & $35.7 \%$ & $100 \%$ \\
\hline 1960 & $13.2 \%$ & $7 \% * *$ & $55.9 \%$ & $23.9 \% * *$ & $100 \%$ \\
\hline
\end{tabular}

SOURCES : 1874 et 1888: André Labarrère-Paulé, Les instituteurs laïques au Canadafrançais 1836-1900, Québec, PUL, 1965, pp. 299 et 357.

1900, 1940, 1960: Maryse Thivierge, Les institutrices laiques à l'école primaire catholique au Québec, de 1900 à 1904, Thèse de Ph. D., Université Laval, 1981, p. 39.

* Ce chiffre comprend les protestants.

** Ce chiffre ne comprend pas les professeurs du niveau post-primaire (écoles normales, écoles spéciales, collèges classiques, etc.), religieux à $100 \%$ sauf en 1960 , alors que les laïcs commencent à envahir ces secteurs.

Statistiquement, les religieuses n'ont jamais été majoritaires face aux institutrices. L.P. Audet avance qu'au début des années 1940, laïss et religieux étaient également répartis en termes d'effectifs ${ }^{13}$. Cela est vraisemblable. À partir de cette époque toutefois, la proportion des religieux est allée en diminuant jusqu'à la réforme Parent.

Par ailleurs, on ne doit pas perdre de vue que le réseau des écoles primaires comprend longtemps un nombre considérable d'écoles de rang où on ne retrouve aucune religieuse, ce qui relativise quelque peu la prépondérance numérique des institutrices. En effet, simultanément, les religieuses dominent largement le personnel du primaire-complémentaire et du primaire-supérieur, l'enseignement post-primaire et l'enseignement spécialisé. En 1960, elles détiennent encore $47 \%$ de tous les postes

\footnotetext{
${ }^{13}$ Louis-Philippe Audet, Histoire de l'enseignement au Québec, Montréal, Holt, Rinehart \& Winston, 1971, Tome 2, p. 319. Dans ce tableau, Audet n'identifie pas quets réseaux sont couverts par ses données.
} 
de direction de tout le secteur public (primaire et secondaire, catholique et protestant, masculin et féminin) soit 1154 postes sur $2450{ }^{14}$.

Tentant d'évaluer quantitativement la présence des congrégations enseignantes féminines en 1960, nous avons exploré de nouveau le Canada ecclésiastique. Nous avons obtenu le panorama suivant, tel qu'illustré par le tableau 10. La diversité des institutions est spectacu-

TABLEAU 10. Panorama des activités éducatives des congrégations religieuses enseignantes féminines au Québec en 1960

\begin{tabular}{|l|r|c|}
\hline Nature des institutions & $\begin{array}{c}\text { Nombre } \\
\text { d'institutions }\end{array}$ & $\begin{array}{c}\text { Nombre de } \\
\text { congrégations } \\
\text { impliquées }\end{array}$ \\
\hline Écoles primaires & 1134 & 51 \\
\hline Écoles secondaires & 96 & 17 \\
\hline Couvents (pensionnats) & 253 & 32 \\
\hline Orphelinats - écoles & 44 & 11 \\
\hline Jardins de l'enfance & 14 & 6 \\
\hline Écoles maternelles & 13 & 3 \\
\hline Cours latin-sciences (classique 1er degré) & 50 & 11 \\
\hline Écoles normales & 65 & 26 \\
\hline Scolasticats & 33 & 33 \\
\hline Instituts familiaux & 46 & 23 \\
\hline Collèges classiques (2e degré) & 18 & 11 \\
\hline Écoles d'infirmières & 23 & 7 \\
\hline Écoles d'infirmières-auxiliaires & 6 & 3 \\
\hline Écoles supérieures de secrétariat & 13 & 8 \\
\hline Écoles d'art (musique et dessin) & 8 & 7 \\
\hline Écoles pour handicapés & 6 & 5 \\
\hline Écoles de réforme & 7 & 4 \\
\hline Facultés universitaires & 5 & 3 \\
\hline TOTAL & 1834 & 67 \\
\hline
\end{tabular}

SOURCE: Le Canada ecclésiastique, 1960.

${ }^{14}$ Rapport du Surintendant de l'instruction publique, 1960. 
laire. Comme on le verra, les responsables du D.I.P. ont investi peu d'efforts dans le développement de l'éducation des filles. Mais les congrégations religieuses $\mathrm{y}$ ont mis beaucoup de dynamisme et de réalisme. Dès la fin du XIX ${ }^{\mathrm{e}}$ siècle, elles cherchent à allonger la scolarité offerte aux filles. De plus, leur rôle dans la formation professionnelle des filles est évident: elles forment $100 \%$ des institutrices francophones, 90\% des infirmières et un nombre impossible à évaluer de secrétaires. Le secteur de l'enseignement technique et professionnel féminin est malheureusement encore largement inexploré ${ }^{15}$. C'est pourquoi nous nous limiterons dans la section suivante à examiner l'action des congrégations enseignantes dans le développement de l'enseignement secondaire et supérieur.

\section{DIVERSIFICATION DES RÔLES DES RELIGIEUSES ENSEIGNANTES (1850-1960)}

Cette entreprise est malaisée car plusieurs phénomènes se développent simultanément, parfois convergents, parfois divergents, et réagissent l'un sur l'autre. Nous allons, dans cette brève synthèse en examiner trois: l'initiative des autorités éducatives, celles des congrégations enseignantes féminines et la formation des religieuses enseignantes. Trois périodes se dégagent: la première caractérisée par l'inertie des autorités face à l'éducation des filles; la seconde où se modifient les règles du jeu établies au $\mathrm{XIX}^{\mathrm{e}}$ siècle; la troisième créée par la conjoncture reliée à la loi de l'obligation scolaire.

\section{Période 1850-1899}

$\mathrm{Au} \mathrm{XIX}^{\mathrm{e}}$ siècle, on constate sans difficulté un certain désengagement des principales instances administratives publiques face à l'éducation, et surtout face à l'instruction des filles. Par exemple, l'abolition du Ministère de l'instruction publique, en 1875, peut être présentée comme «une démission volontaire de l'État" ${ }^{16}$. Préoccupé par l'émigration des Québécois, par l'ouverture de nouveaux territoires de colonisation et

\footnotetext{
15 Jean-Pierre Charland, Histoire de l'enseignement professionnel, Québec, I.Q.R.C., 1982, ignore l'enseignement professionnel destiné aux filles; Marcel Fournier, Entre l'école et l'usine, Montréal, Éditions coopératives Albert Saint-Martin/C.E.Q., 1980, commet la même omission. Pourtant leurs statistiques sur la situation récente présentent d'importantes cohortes féminines qui ne sont vraisemblablement pas apparues du jour au lendemain. Le mystère reste entier car jusqu'ici, notre recherche n'a pu couvrir adéquatement ce secteur livré à l'entreprise privée.

${ }^{16}$ Ruby Heap, L'Église, l'État et l'éducation au Québec 1875-1898, thèse de M.A., Université McGill, Montréal, 1978, p. 100.
} 
la construction de chemins de fer, le gouvernement du Québec avait des priorités autres que l'instruction des jeunes. Cela transparaît d'ailleurs dans les slogans électoraux de l'époque où l'enseignement «à rabais" ou "bon marché» ${ }^{17}$ est un leit-motiv constant. Dans ce contexte, l'État provincial se décharge en grande partie de ses responsabilités financières en les faisant assumer par les commissions scolaires.

Une commission scolaire comme celle de Montréal offre un bon exemple de ce qui se passe alors. À la fin du $\mathrm{XIX}^{e}$ siècle, les administrateurs de la C.E.C.M. désirent éviter une cléricalisation intégrale du corps professoral enseignant aux garçons.

Pour ce faire, les commissaires s'efforcent de réaliser des économies dans les écoles administrées par des congrégations religieuses. L'objectif de ces économies sera de pouvoir offrir de bons salaires aux hommes et ainsi les attirer et les retenir dans la profession de l'enseignement. Il en résulte que, durant toute la deuxième moitié du $\mathrm{XIX}^{\mathrm{e}}$ siècle, la C.E.C.M. dépense six à dix fois plus pour l'instruction des garçons que pour celle des filles. Dans les écoles laïques, le coût annuel par élève varie chez les garçons entre $9,33 \$$ et $16,78 \$$; chez les filles, il oscille entre $1,30 \$$ et $4,48 \$$. Au XIX ${ }^{\mathrm{e}}$ siècle, la C.E.C.M. construit elle-même des écoles pour les garçons. Pour les filles, cette entreprise est laissée aux soins des congrégations religieuses ${ }^{18}$. Ailleurs en province, la priorité aux religieux(ses) et la discrimination envers les institutrices lä̈ques sont aussi les principaux moyens utilisés pour développer «économiquement" l'instruction publique.

À la même époque, on observe également une grande imprécision dans les programmes d'études. Les niveaux d'étude sont les cours élémentaire, modèle et académique. Le contenu de ces programmes et leur scolarité théorique ne sont établis définitivement qu'en 1888 par le Département de l'instruction publique. Il faudrait d'ailleurs immédiatement ajouter que la scolarité déterminée en 1888 pour les différents cours d'études ne peut s'appliquer concrètement et que, par exemple, le cours élémentaire ne peut être couvert en quatre ans tel que le D.I.P. le propose: l'expérience a prouvé qu'il faut sept ans d'école à la plupart des enfants pour faire le cours élémentaire. Quelques-uns en prendront huit, un plus petit nombre six ${ }^{19}$.

\footnotetext{
${ }^{17}$ Ibid., p. 500.

${ }^{18}$ Marta Danylewycz, «Sexes et classes sociales dans l'enseignement: le cas de Montréal à la fin du XIX ${ }^{e}$ siècle» dans Maîtresses de maison, pp. 93-118.

${ }^{19}$ A.N.Q., Fonds des écoles primaires, Esquisse de l'évolution des programmes des écoles catholiques de 1888 a 1943, textes dactylographiés, (s.d.), vol. 1, pp. 3, 89, 306, $323,247,348$.
} 
Il faut enfin souligner qu'en 1846, une mesure avait été adoptée concernant les enseignants-religieux. Cette mesure stipulait que religieuses et religieux n'étaient pas tenus de posséder un brevet pour enseigner ${ }^{20}$. Bénéfique à court terme car il permettait aux congrégations enseignantes d'accueillir des novices ne détenant aucun diplôme quitte à les former par la suite, ce règlement allait, au $\mathrm{XX}^{\mathrm{e}}$ siècle, engendrer de multiples casse-tête, notamment pour les administratrices des congrégations de femmes. Nous en reparlerons.

Cet ensemble de facteurs et surtout le manque de rigueur des structures de l'enseignement public laisse alors une marge de manoeuvre confortable aux congrégations enseignantes de femmes. Chaque congrégation élabore donc son programme-maison (Tableau 11). D'une congrégation à l'autre, les terminologies varient: cours gradué, cours sousgradué, cours supérieur; ces termes ne désignent pas nécessairement des programmes et des années d'études identiques. Chaque congrégation tient cependant à ce que ses finissantes soient conscientes d'avoir effectué un cycle complet et terminal d'études et marque cette volonté par les appellations soit de cours gradué, soit de cours supérieur. Pourtant, aucun de ces diplômes n'est reconnu ou sanctionné officiellement. Tous sont des diplômes-maison ne donnant accès ni à des études supérieures ni au marché du travail.

Cependant, les jeunes filles qui poursuivent ces études peuvent obtenir des diplômes officiels. En effet, en se présentant devant un bureau régional d'examinateurs, elles sont en mesure de passer les examens permettant l'obtention des brevets d'écoles élémentaire, modèle ou académique sanctionnés par le ministère ou le Département de l'instruction publique ${ }^{21}$. Il faut noter que ces brevets d'enseignement sont, à la fin du $\mathrm{XIX}^{\mathrm{e}}$ siècle, les seuls diplômes accessibles aux filles. D'autre part, il semble bien que l'on puisse affirmer, dans l'état actuelle des recherches, que le diplôme d'école académique, en théorie accessible aux jeunes filles fréquentant l'école publique, ne pouvait en fait être obtenu que par des études dans une institution privée ${ }^{22}$. En outre, les archives des congrégations de religieuses enseignantes laissent entrevoir que leur programme-maison ne se voulait pas limité au programme du cours académique mais tendait à le dépasser quand cela ne serait que par le refus de l'étiqueter «cours académique». Au

${ }^{20}$ Statuts refondus du Bas-Canada, chap. 15, section 110, par. 10.

${ }^{21}$ De 1867 à 1875, il s'agit du Ministère de l'instruction publique, après cette date, du Département du même nom.

${ }^{22}$ Toutes les monographies consacrées à des pensionnats attestent cette affirmation. 
Tableau 11. Comparaison des niveaux d'études dans les pensionnats de filles (1844-1915)

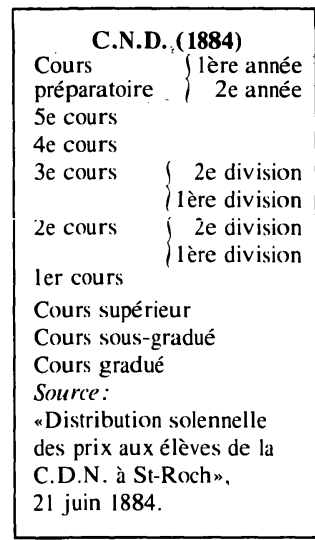

\begin{tabular}{|l|}
\hline \multicolumn{1}{|c|}{ S.N.J.M. (1894) } \\
Cours préparatoire \\
6e classe \\
5e classe \\
4e classe \\
3e classe \\
2e classe \\
lère classe \\
\\
Cours $\quad\{$ lère annéc \\
supérieur \\
2e année \\
Source: \\
Plan d'études, 1894.
\end{tabular}

\begin{tabular}{l}
$\begin{array}{l}\text { SOEURS DE STE-ANNE } \\
\text { (1907) }\end{array}$ \\
$\begin{array}{l}\text { Classe enfantine } \\
\text { lère année } \\
\text { Cours } \\
\text { élémentaire }\end{array}$ \\
$\begin{array}{l}\text { Cours } \\
\text { moyen }\end{array} \quad\left\{\begin{array}{l}2 \mathrm{e} \text { année } \\
3 \mathrm{e} \text { année } \\
5 \mathrm{e} \text { année }\end{array}\right.$ \\
$\begin{array}{l}\text { Cours } \\
\text { supérieur }\end{array}$ \\
$\begin{array}{l}\text { Source: } \\
\begin{array}{l}\text { Cours d'études des Soeurs } \\
\text { de Ste-Anne }\end{array}\end{array}$ \\
\hline $\begin{array}{l}7 \mathrm{e} \text { année } \\
8 \mathrm{e} \text { année }\end{array}$
\end{tabular}

\begin{tabular}{|l|l|}
\hline \multicolumn{1}{|c|}{$\begin{array}{l}\text { C.N.D. (1910) } \\
\text { Cours } \\
\text { élémentaire }\end{array}$} & $\begin{array}{l}\text { lère année } \\
\text { 2e année } \\
\text { 3e annéc } \\
4 \mathrm{e} \text { année }\end{array}$ \\
$\begin{array}{l}\text { Cours } \\
\text { modèle }\end{array}$ & $\left\{\begin{array}{l}5 \mathrm{e} \text { année } \\
6 \mathrm{e} \text { année }\end{array}\right.$ \\
$\begin{array}{l}\text { Cours } \\
\text { académique }\end{array}$ & $\left\{\begin{array}{l}\text { 7e année } \\
8 \mathrm{e} \text { année (Cours supérieur) }\end{array}\right.$ \\
$\begin{array}{l}\text { Cours sous-gradué } \\
\text { Cours gradué }\end{array}$ \\
$\begin{array}{l}\text { Source: } \\
\text { Programme des études, C.N.D. Mtl, 1910 }\end{array}$ \\
\hline
\end{tabular}

\begin{tabular}{l} 
URSULINES (1912-1913) \\
7e année - Classe préparatoire \\
6e année \\
5e année \\
4e année \\
3e année \\
2e année \\
lère année \\
Classe du Brevet modèle \\
Cours supérieur: 1 an \\
\\
Source: \\
Boîte "Cahiers d’élèves" 1912-1913. \\
Archives des Ursulines. \\
\hline
\end{tabular}

\begin{tabular}{|c|c|}
\hline $\begin{array}{l}\text { Srs de JI } \\
\text { Cours } \\
\text { élémentaire }\end{array}$ & 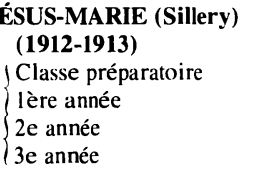 \\
\hline $\begin{array}{l}\text { Cours } \\
\text { intermédiaire }\end{array}$ & $\left\{\begin{array}{l}1 \text { ère année } \\
2 \mathrm{e} \text { année (Brevet modèle) }\end{array}\right.$ \\
\hline $\begin{array}{l}\text { Cours } \\
\text { supérieur }\end{array}$ & $\left\{\begin{array}{l}\text { lère année } \\
2 \mathrm{e} \text { année }\end{array}\right.$ \\
\hline \multicolumn{2}{|c|}{ Cours gradué: 1 an } \\
\hline $\begin{array}{l}\text { Source: } \\
\text { Boîte “Cahie } \\
\text { Archives des }\end{array}$ & $\begin{array}{l}\text { rs d'élèves" 1912-1913. } \\
\text { Ursulines. }\end{array}$ \\
\hline
\end{tabular}

\begin{tabular}{|c|c|}
\hline $\begin{array}{l}\text { SOEUR } \\
\text { Cours } \\
\text { élémentaire }\end{array}$ & $\begin{array}{l}\text { SS DE SAINTE-CROIX } \\
\text { (CA 1915) } \\
\left\{\begin{array}{l}\text { lère année } \\
2 \mathrm{e} \text { année } \\
3 \mathrm{e} \text { année } \\
4 \mathrm{e} \text { année }\end{array}\right.\end{array}$ \\
\hline $\begin{array}{l}\text { Cours } \\
\text { intermédiaire }\end{array}$ & $\left\{\begin{array}{l}5 e \text { année } \\
6 \text { e année }\end{array}\right.$ \\
\hline $\begin{array}{l}\text { Cours } \\
\text { supérieur }\end{array}$ & $\left\{\begin{array}{l}7 \mathrm{e} \text { année } \\
\{\mathrm{e} \text { année }\end{array}\right.$ \\
\hline $\begin{array}{l}\text { Cours } \\
\text { gradué }\end{array}$ & $\left\{\begin{array}{l}\text { lère année } \\
2 \mathrm{e} \text { année }\end{array}\right.$ \\
\hline \multicolumn{2}{|c|}{$\begin{array}{l}\text { Source: } \\
\text { Règlement - Cours gradué, (s.d.) }\end{array}$} \\
\hline
\end{tabular}


demeurant, les religieuses sont les seules à offrir le cours académique aux francophones au XIX ${ }^{\mathrm{e}}$ siècle ${ }^{23}$.

L'instruction des filles repose donc dans une large mesure sur les épaules des congrégations religieuses de femmes autant pour la construction des écoles que pour l'établissement des programmes. Pour arriver à faire face aux obligations financières que nécessite une pareille prise en charge, les religieuses se devront d'assurer leur survie matérielle. Elles y parviendront en implantant dans diverses paroisses, des pensionnats indépendants dont les revenus procurent une certaine stabilité à la communauté. C'est ce qui a été démontré dans la paroisse SaintJean-Baptiste de Montréal où les recettes tirées de l'école privée, l'Académie Marie-Rose, permettaient aux religieuses des Saints-Noms-deJésus-et-de-Marie d'assumer concurremment l'enseignement à l'école publique ${ }^{24}$. Ce modèle de financement du réseau public par le réseau privé fut probablement assez répandu au $\mathrm{XIX}^{\mathrm{e}}$ siècle dans les institutions dirigées par les religieuses ${ }^{25}$. Il semble que les religieuses aient tablé sur les différences sociales pour s'assurer une clientèle payante.

Les pensionnaires avaient été entièrement séparées des quarts de pension, ce qui donnait un grand avantage au Pensionnat, permettant un meilleur choix d'élèves et offrant plus de facilités pour les mieux former à la vie chrétienne et sociale. Toutes les distinctions et les privilèges étant réservés aux pensionnaires, les premières familles de la ville et des environs tinrent à l'honneur de faire élever leurs enfants au Couvent et depuis le pensionnat n'a fait qu'augmenter. ${ }^{26}$

La scolarité plus longue et l'appellation "cours gradué» devaient compter également dans l'incitation à fréquenter le pensionnat.

\footnotetext{
${ }^{23}$ D'après les Rapports du Surintendant de l'instruction publique. Les filles fréquentant des académies laïques sont des anglophones inscrites dans des académies mixtes.

${ }^{24}$ Marie-Paule Malouin, L'Académie Marie-Rose 1876-1911, mémoire de M.A. Université de Montréal, 1980, pp. 77-9 (voir aussi note 4).

${ }^{25} \mathrm{La}$ démonstration établie par Marie-Paule Malouin dans sa recherche sur l'Académie Marie-Rose est corroborée par plusieurs des monographies de notre groupe, notamment celle de Ruby Heap sur les Soeurs de la Charité de Québec, celle de Joanne Daigle sur les Ursulines de Trois-Rivières, et la thèse déjà citée de Jacques Desgrandchamps qui explique le même processus pour six congrégations distinctes du diocèse de Sherbrooke au XIX ${ }^{\mathrm{e}}$ siècle.

${ }^{26}$ Annales du Mont Notre-Dame de Sherbrooke, I, 1880, cité par J. Desgrandchamps, $M^{\mathrm{gr}}$ Antoine Racine, p. 23.
} 
Il semble bien aussi que ce phénomène était vécu sans qu'on en saisisse toute la portée. Compte tenu des salaires dérisoires versés aux religieuses enseignantes dans le réseau public d'enseignement, seules les institutions privées garantissaient la survie des congrégations. Cette survie assurée, une partie des effectifs enseignants de chaque congrégation était en mesure de prendre en charge l'enseignement aux enfants fréquentant les écoles publiques. Au XIX ${ }^{\mathrm{e}}$ siècle, tout se passe donc comme si le secteur privé finançait en quelque sorte le secteur public dans le domaine de l'instruction des filles - surtout quand on compare avec les efforts des religieux et le gouvernement pour développer l'enseignement offert aux garçons.

Période 1899-1939

Dès 1893, des membres du Conseil de l'instruction publique avaient tenté d'abolir le règlement de 1846 qui permettait aux religieux(ses) d'enseigner sans brevet ${ }^{27}$. L'échec de cette tentative ${ }^{28}$ entraîne toutefois en 1899 l'abolition des bureaux régionaux d'examinateurs et la création d'un bureau central pour ceux et celles qui veulent obtenir un brevet d'enseignement. Ce changement de structure visait évidemment à uniformiser la formation des enseignants et par conséquent, impliquait une conformité plus poussée des programmes des pensionnats aux exigences du Département de l'instruction publique. C'est dans ce contexte que s'explique la création et l'expansion du réseau catholique des écoles normales de filles. On compte une seule école normale de filles en 1898, sept en 1908, onze en 1918, dix-sept en 1928 et vingt-trois en $1938{ }^{29}$. Par ailleurs, une décision du Conseil de l'instruction publique, en 1913, stipule que dorénavant les examens du bureau central se feront d'après les programmes en vigueur dans les écoles normales de garçons ${ }^{30}$.

\footnotetext{
${ }^{27}$ Thomas Chapais, Les congrégations enseignantes et le brevet de capacité, Québec, Brousseau, 1893, p. 9.

${ }^{28}$ Des supérieures générales font parvenir à l'Archevêque de Montréal de longs réquisitoires sur cette question. Voir entre autres, Histoire de la Congrégation Notre-Dame, vol. 10 , tome 2, pp. 497-507.

${ }^{29}$ Les informations qui suivent sont tirées du livre de Jeannette Létourneau, Les écoles normales de filles au Québec, Montréal, Fides, 1981, 239 p.

${ }^{30}$ A.U.C.R.F.*, Boîte 298, Notes relatives aux études, respectueusement soumises à Notre Mère générale et aux mères conseillères, Manuscrit, janvier 1914, p. 2.

* Pour éviter que certains documents ne soient mal interprétés, nous avons identifié un fonds d'archives particulier, par le sigle - A.U.C.R.F.: Archives d'une congrégation religieuse féminine.
} 
Ce mouvement se trouvait à avaliser en quelque sorte l'extension de la scolarité offerte aux filles par les religieuses. L'opinion publique, l'État et le clergé étaient, dans l'ensemble, favorables à la fréquentation des écoles normales par des jeunes filles. Pourtant, lorsque l'on compare le traitement réservé aux écoles normales de garçons à celui des mêmes institutions pour jeunes filles, on constate certaines discriminations. Ainsi, par exemple, les écoles normales Jacques-Cartier et Laval destinées aux garçons furent aménagées dans des locaux appartenant au gouvernement. Pour les filles, les Ursulines et, plus tard, les Dames de la Congrégation durent elles-mêmes fournir les locaux. Entre 1899 et 1922, quand une nouvelle école normale de filles est ouverte, elle est généralement établie dans un pensionnat aménagé à cette fin. Quand il faut construire un édifice, les religieuses en assument les frais. En fait, "... le gouvernement provincial ne bâtit pas lui-même les écoles normales de filles et il n'en prend pas la responsabilité financière" ${ }^{31}$. Cette parcimonie de l'État se reflète également au niveau des subventions accordées aux écoles normales. Ainsi, en 1907-08, les quatre écoles normales catholiques de filles ne reçoivent que $38 \%$ de la subvention globale destinée aux écoles normales catholiques. Ces quelques exemples permettent de saisir que, même dans l'enseignement normal, les congrégations religieuses féminines eurent à surmonter des difficultés que le consensus à propos de la légitimité des études des filles dans ce type d'institutions ne permettait pas d'entrevoir.

Ainsi, les pressions du D.I.P. et celles du Conseil de l'instruction publique menaçaient à plus ou moins long terme de transformer une très grande majorité des pensionnats fondés par les religieuses en autant de "mini" écoles normales. Il ne semble pas que les congrégations religieuses féminines aient été pleinement d'accord avec cette canalisation des études des filles dans le seul champ de l'enseignement. Elles désiraient ouvrir d'autres voies à l'activité des filles. Déjà, les Ursulines en inaugurant à Roberval une première école ménagère avait lancé un type d'institution qui se répandra surtout après la fondation du cours classico-ménager par les Dames de la Congrégation à Saint-Pascal en $1905^{32}$. C'est également à la même époque qu'à la suite des hôpitaux anglophones, les religieuses hospitalières francophones ouvriront les

\footnotetext{
${ }^{31} \mathrm{M}^{\mathrm{gr}}$ J.A. Archambault, "L'École normale de jeunes filles à Joliette" dans Lettres pastorales, Mandements et circulaires de $\mathrm{M}^{\mathrm{gr}}$ J.A. Archambault, vol. III, no 8, pp. 162-3.

${ }^{32} \mathrm{~N}$. Thivierge, Écoles ménagères et instituts familiaux: un modèle féminin traditionnel, Québec, I.Q.R.C., 1982, 475 p.
} 
premières écoles d'infirmières ${ }^{33}$. De la même façon, la mise sur pied des différentes écoles commerciales pour jeunes filles se situe durant la même période. Malheureusement la recherche est encore très incomplète à ce niveau. Il en est de même pour les différentes écoles supérieures de musique dont les programmes se structurent aussi durant le premier tiers du $\mathrm{XX}^{\mathrm{e}}$ siècle.

L'ensemble de ces cours permettait donc aux jeunes filles de s'orienter ailleurs que dans l'enseignement. Cependant, pour les congrégations religieuses féminines, ces programmes étaient insuffisants pour contrer ce qui leur semblait une ingérence du D.I.P. dans les programmes de leur congrégation. Désirant sans doute conserver leurs distances face au pouvoir public, refusant de transformer tous leurs pensionnats en "mini» écoles normales, elles se tournent vers les administrations universitaires. Dans une lettre collective, signée par les maîtresses générales des études des Soeurs de Sainte-Anne, de Sainte-Croix et des Saints Noms-de-Jésus-et-de-Marie, les différentes communautés demandent à la Faculté des arts de l'Université Laval (à Montréal) d'accorder un certificat officiel aux finissantes de leur cours d'études. Ce cours sera celui de Lettres-Sciences ${ }^{34}$. Grâce à lui, les programmes des pensionnats gardent une certaine autonomie par rapport à ceux que le D.I.P. semblait leur imposer. Plus encore, le cours de Lettres-Sciences offre un diplôme dont la scolarité et la valeur sont plus élevés que le plus haut brevet d'enseignement ${ }^{35}$.

Or, en 1923 et surtout en 1929, se produit une réforme qui risque de mettre en péril la suprématie du cours de Lettres-Sciences par rapport aux autres programmes d'études. Ces années-là, en effet, le cours primaire se transforme et s'allonge dans le secteur public ${ }^{36}$. Avec ses douze années de scolarité, il risque de déclasser le cours de LettresSciences qui en exige onze seulement. De leur côté, les écoles normales ont atteint la durée de scolarité du cours Lettres-Sciences: ainsi, en 1934, pour les filles, un minimum de onze années d'études est exigé pour l'obtention du brevet supplémentaire.

\footnotetext{
${ }^{33}$ E. Desjardins, S. Giroux et E.C. Flanagan, Histoire de la profession infirmière au Québec, Montréal, Association des infirmières et infirmiers du Québec, 1970, pp. 111-112.

${ }^{34}$ A.U.C.R.F., Boîte 300, «Lettre collective au secrétariat de l’Université Laval de Montréal », 18 mars 1916.

${ }^{35}$ Les désignations des brevets d'enseignement changent durant la période: les plus élevés seront l'académique jusqu'en 1923, le complémentaire jusqu'en 1929, le supplémentaire jusqu'en 1937.

${ }^{36}$ C'est la création du primaire-complémentaire en 1923 et du primaire supérieur en 1929. Dans les faits, un nombre minime de filles peut accéder à ces programmes.
} 
C'est dans ce contexte que se situe l'implantation d'un réseau de collèges classiques féminins. Certes, le collège Marguerite-Bourgeoys était fondé depuis 1908. Il avait fallu attendre jusqu'en 1925 pour que s'ouvre le Collège Jésus-Marie de Sillery dans la région de Québec. Mais entre 1932 et 1938 , le rythme des fondations s'accélère et huit nouveaux collèges féminins voient le jour ${ }^{37}$.

Ce n'est certes pas le contexte économique de la décennie qui peut expliquer cette étonnante floraison. Et ce ne peut être non plus un soudain intérêt des facultés des arts pour l'enseignement classique offert aux filles. Les recherches, en effet, permettent de documenter longuement les réticences des responsables masculins face au baccalau=éat féminin ${ }^{38}$, alors qu'au même moment l'Université Laval accordait les affiliations pour le cours dit «classico-ménager» ${ }^{39}$. Nous faisons l'hypothèse que voulant maintenir leurs distances avec le secteur public, continuer d'offrir dans leurs pensionnats une scolarité plus longue, et surtout garder chez elles «leurs» finissantes, chaque congrégation a tenu à obtenir son cours classique identique à celui des garçons. C'est le Collège Marie-Anne qui donne le coup d'envoi de cette série de fondations. Cela n'ira pas sans mal. L'archevêché de Montréal hésite à donner son approbation. Or, celle-ci est indispensable pour obtenir l'affiliation à l'université. Les pressions des Soeurs de Sainte-Anne conjuguées à l'appui de Mère Sainte-Anne-Marie finiront par enlever la décision ${ }^{40}$. Un compromis sera accepté: les élèves du futur Collège Sainte-Anne suivront leurs cours chez les Soeurs de Sainte-Änne mais devront passer leurs examens au Collège Marguerite-Bourgeoys. Le leitmotiv "Il ne faut pas multiplier les collèges féminins" ne résistera pas, par la suite, aux demandes de différentes congrégations voulant fonder leur propre institution, car un précédent a été créé. Chaque congrégation exploitera, en rencontrant des résistances parfois, la brèche créée par l'ouverture d'un deuxième collège féminin à Montréal.

\footnotetext{
${ }^{37}$ Claude Galarneau, Les collèges classiques au Canada français, Fides, 1978, horstexte.

${ }^{38}$ Lucienne Plante, L'enseignement classique à la Congrégation de Notre-Dame (19081971), thèse de Ph. D., Université Laval, 1971.

39 Abbé Honorius Provost, "Historique de la Faculté des Arts de l'Université Laval 1852-1952 " dans L'enseignement secondaire au Canada, Québec, Université Laval, 1952, pp. 1-2.

${ }^{40}$ Michèle Jean, «L'enseignement supérieur des filles et son ambiguïté: le Collège Marie-Anne, 1932-1958» dans Maîtresses de maison, pp. 145-152. Mère Sainte-AnneMarie, c.n.d. est la fondatrice du Collège Marguerite Bourgeoys.
} 
C'est dans le même esprit que plusieurs congrégations cherchent à améliorer leur programme-maison en sollicitant les autorisations des facultés universitaires. C'est le cas des Soeurs de l'Assomption qui, affiliées à l'Université Laval, ne sont pas autorisées à offrir le cours Lettres-sciences. La maîtresse générale des études écrit:

...Vous pouvez constater, monsieur le secrétaire, que les modifications $[\ldots]$ ne tendent pas à affaiblir le programme. Nous désirons en effet, que tout en se rapprochant de celui du Bureau central, il gardc un degré de supériorité qui lui permette de soutenir avantageusement la comparaison avec le programme des instituts affiliés à l'Université de Montréal, avec celui des classes primaire supérieure de $9 \mathrm{e}, 10 \mathrm{e}$ et $11 \mathrm{e}$ années, et avec le «Program for the English Speaking Catholic High School» auquel est emprunté celui de l'enseignement moyen. ${ }^{41}$

La période 1899-1939 en est donc une de floraison d'institutions et de programmes qui permettent aux jeunes filles d'accéder à des études dont la scolarité est de plus en plus poussée. Cet allongement de la scolarité des filles implique, pour les religieuses enseignantes, l'obligation de poursuivre elles-mêmes leurs études. Or la loi de 1846 est toujours en vigueur et nulle enseignante religieuse n'est tenue de détenir un brevet d'enseignement. Il $\mathrm{y}$ a là un problème qui incite les directrices générales des études à inciter vigoureusement leurs enseignantes à se munir de brevets. Mais, elles rencontrent des résistances. L'une d'elles écrit:

Il est évident que nous avons et que nous aurons encore longtemps des maîtresses qui ne sont pas à la hauteur de leur tâche; il est évident aussi que les études pédagogiques du noviciat ne durent qu'une année - il serait plus juste de dire neuf mois en soustrayant toutes les leçons perdues par les vacances trop longues et les corvées que trop souvent les novices sont appelées à donner au détriment de leur classe - il est évident que ces études ne sauraient suffire à former de bonnes maîtresses. ${ }^{42}$

On stigmatise «les routinières - celles qui enseignent aujourd'hui comme on le faisait il y a vingt ans, et qui refusent d'entrer dans le mouvement pédagogique $-\ldots{ }^{43}$. Une maîtresse générale des études

\footnotetext{
${ }^{41}$ Archives de la Maison Mère des Soeurs de l'Assomption de la Sainte-Vierge, "Lettre des S.A.S.V. à l'abbé Arthur Maheux, secrétaire de l'Université Laval, 23 octobre 1933».

${ }^{42}$ A.U.C.R.F., Rapport sur les études 1908-1914, pp. 2-3.

${ }^{43}$ A.U.C.R.F., Décisions capitulaires, 1914, p. 4.
} 
encourage les religieuses enseignant à un niveau particulier et ne possédant pas ce diplôme à se préparer pour obtenir ce brevet du bureau central des examinateurs. Par exemple, les «maîtresses munies d'un diplôme modèle, qui enseignent les classes de $7 \mathrm{e}$ et $8 \mathrm{e}$ années, et, en conséquences, préparent plus ou moins directement les élèves pour le brevet académique suivront le programme de leurs élèves... ${ }^{44}$. Il en va de même pour celles qui enseignent aux cours modèle et élémentaire sans en détenir le diplôme. Malgré ces incitations, une proportion importante de religieuses ne détiennent pas de brevets d'enseignement. Dans une communauté, en 1924, sur un total de 514 enseignantes, 169 religieuses ne détiennent aucun diplôme ${ }^{45}$; en 1928 , la situation ne s'est pas améliorée; 303 institutrices des 552 que compte la communauté n'ont pas de brevet d'enseignement.

En fait, si les responsables des congrégations insistent auprès de leurs religieuses pour qu'elles soient légalement qualifiées, ce n'est pas uniquement pour s'assurer de la valeur de l'enseignement mais surtout parce qu'elles veulent "prévenir les exigences gouvernementales" ${ }^{46}$. Cette loi de 1846 qui a eu comme conséquence une acceptation officielle de l'absence de qualification d'une proportion non négligeable des institutrices religieuses est maintenant ressentie comme une constante épée de Damoclès. On le reconnaît: «ce brevet ne donnera à la plupart des maîtresses ni plus d'autorité, ni plus de capacité, mais il servira beaucoup à la communauté qui aura besoin de produire avant longtemps peut-être des statistiques sur son personnel enseignant" ${ }^{47}$. Les religieuses ne se sentent pas tellement menacées par l'État québécois - qui ne montre aucune veilléité d'abroger la loi de 1846; elles craignent les autorités locales, i.e. les commissions scolaires. "Lorsque MM. les Commissaires paieront un salaire plus élevé aux maîtresses pourvues de certificats de pédagogie, ils seront par ce fait même renseignés sur la capacité du personnel enseignant des congrégations religieuses, et ils exigeront ce qu'ils ont le droit d'avoir, des maîtresses préparées..." ${ }^{48}$ Or, la perspective de la disparition à brève échéance du bureau central des examinateurs rendait plus difficile encore la qualification des institutrices religieuses en fonction. Informées de la future disparition du

\footnotetext{
${ }^{44}$ A.U.C.R.F., «Lettre de la maîtresse générale des études », 1er octobre 1914, p. 1.

${ }^{45}$ A.U.C.R.F., Rapport des études, 1921-1924, p. 8; 1922-28, p. 36.

${ }^{46}$ A.U.C.R.F., Décisions capitulaires, 1914, p. 6.

${ }^{47}$ A.U.C.R.F., "Lettre de la maîtresse générale des études ", 18 février 1916, p. 1.

${ }^{48}$ A.U.C.R.F., "Lettre de la directrice générale des études», 27 novembre 1918, pp. 1-3.
} 
bureau central dès 1936, la plupart des communautés de religieuses enseignantes établissent leur propre scolasticat dont les premiers sont officiellement reconnus' en 1937.

S'il fallait pallier d'une façon ou d'une autre aux problèmes causés aux communautés par la loi de 1846, soit par le biais de brevets octroyés par le bureau central des examinateurs soit par les fondateurs de scolasticats-écoles normales, il fallait également assurer la formation des religieuses qui, détenant déjà les plus avancés. L'ouverture de l'Institut pédagogique par la Congrégation Notre-Dame en 1916, puis son affiliation à l'Université de Montréal, en 1926, permit aux religieuses enseignantes de se perfectionner. Vers la même époque, l'Université de Montréal permit aux religieuses enseignantes d'obtenir leur baccalauréat graduellement en fractionnant les matières universitaires en huit examens. Grâce à ces facilités offertes aux religieuses, quelques-unes d'entre elles, dans chaque congrégation, se mettront en mesure d'assumer l'enseignement aux étudiantes des collèges classiques féminins. D'autre part, les soeurs enseignantes peuvent aussi obtenir le diplôme de lettres-sciences, en étudiant à temps partiel, alors que leurs études et les examens qui les sanctionnent sont entièrement sous la juridiction de leur congrégation ${ }^{49}$. Ainsi, l'introduction du cours de lettres-sciences dans une communauté lui permettait d'en faire profiter ses sujets. Cet argument est d'ailleurs invoqué lors de la fondation d'un collège classique:

Il est un avantage sur lequel nous nous permettons d'attirer votre attention... C'est la possibilité pour nos jeunes maîtresses, titulaires des classes de Lettres-Sciences, de suivre les cours (du baccalauréat)... Par cette démarche, nous comptons bien répondre à un besoin et surtout contribuer à la formation de notre personnel enseignant. ${ }^{50}$

Un autre motif sous-tend également très souvent la fondation d'écoles normales, de cours Lettres-Sciences ou de collèges classiques féminins. Grâce à ces institutions, les congrégations religieuses espéraient recruter de nouveaux sujets possédant déjà une certaine formation.

À la lumière de ces différentes informations, on peut percevoir que les religieuses enseignantes tentèrent, durant la période 1899-1939, de contrer les pressions extérieures ou les tentatives d'ingérence, qu'elles viennent du D.I.P. ou des commissions scolaires locales. Ce faisant,

${ }^{49}$ A.U.C.R.F., Rapport des études, 1922-1928, p. 3.

${ }^{50}$ A.U.C.R.F., Rapport des études, 1932-1933, pp. 20-1. 
elles ont créé littéralement tout un éventail d'avenues éducatives pour les filles, tout en obligeant les responsables des études à améliorer la qualification du personnel religieux. Au fond, le prolongement et la structuration des programmes féminins sont tributaires d'une scolarisation plus poussée d'une faible partie des religieuses enseignantes, mais également responsables d'un effet d'entrainement sur la formation de l'ensemble des enseignantes religieuses. En effet, les institutions créées pour les étudiantes seront utilisées en vue de perfectionner une partie du personnel enseignant et de recruter de nouveaux sujets de mieux en mieux qualifiés.

\section{Période 1939-1960}

Cette dernière période se caractérise par une conjoncture nouvelle. La loi de l'obligation scolaire, dont la discussion a entraîné une gigantesque consultation, a suscité une refonte complète de tous les programmes, de la scolarité et de la pédagogie. Cette fois, les congrégations religieuses sont consultées, mais le contrôle de leurs propres institutions va sensiblement leur échapper à mesure que l'État prend en charge l'instruction publique.

Comme on s'y attendait depuis déjà quelques années, le bureau central des examinateurs est aboli en 1939. Aussitôt, on assiste à une multiplication des scolasticats-écoles normales. Voici, de cinq en cinq ans, l'évolution de ce réseau chez les religieuses.

TABLEAU 12. Les scholasticats de religieuses (1937-1954)

\begin{tabular}{|l|c|c|c|}
\hline & $\begin{array}{c}\text { Nombre de } \\
\text { scolasticats }\end{array}$ & $\begin{array}{c}\text { Nombre } \\
\text { d'élèves }\end{array}$ & $\begin{array}{c}\text { Nombre de } \\
\text { diplômes }\end{array}$ \\
\hline $1937-38$ & 8 & 59 & 50 \\
\hline $1941-42$ & 28 & 150 & 121 \\
\hline $1945-46$ & 29 & 483 & 175 \\
\hline $1949-50$ & 28 & 431 & 164 \\
\hline $1953-54$ & 33 & 497 & 265 \\
\hline
\end{tabular}

SOURCE: «Écoles normales catholiques. Un siècle d'existence 1857-1957 » dans L'Instruction publique, avril 1957, p. 654.

Alors que s'organisent les scolasticats religieux, les laïcs, de leur côté, engagent la lutte pour obtenir de meilleurs salaires. Entre 1939 et 1945, les syndicats d'enseignants laïques font des gains substan- 
tiels à ce chapitre ${ }^{51}$. Un tableau comparatif permet de saisir le fossé existant alors entre les salaires des enseignantes religieuses et laïques dans quelques régions du Québec.

TABLEAU 13. Salaires moyens des enseignantes catholiques (1945)

\begin{tabular}{|l|c|c|c|}
\hline & \multicolumn{3}{|c|}{ Religieuses } \\
\hline & $\begin{array}{c}\text { école } \\
\text { élémentaire }\end{array}$ & $\begin{array}{c}\text { école } \\
\text { complémentaire }\end{array}$ & $\begin{array}{c}\text { école } \\
\text { supérieure }\end{array}$ \\
\hline C.E.C.M. & $878 \$$ & $833 \$$ & $876 \$$ \\
\hline C.E.C.Q. & $500 \$$ & $500 \$$ & $500 \$$ \\
\hline Outaouais & $553 \$$ & $602 \$$ & $625 \$$ \\
\hline Gaspésie & $546 \$$ & $548 \$$ & $562 \$$ \\
\hline Sherbrooke & $500 \$$ & $572 \$$ & $553 \$$ \\
\hline
\end{tabular}

\begin{tabular}{|l|c|c|c|}
\hline & \multicolumn{3}{|c|}{ Laïques } \\
\hline & $\begin{array}{c}\text { école } \\
\text { élémentaire }\end{array}$ & $\begin{array}{c}\text { école } \\
\text { complémentaire }\end{array}$ & $\begin{array}{c}\text { école } \\
\text { supérieure }\end{array}$ \\
\hline C.E.C.M. & $1680 \$$ & $1673 \$$ & $1900 \$$ \\
\hline C.E.C.Q. & $1465 \$$ & $1396 \$$ & $496 \$$ \\
\hline Outaouais & $654 \$$ & $750 \$$ & -- \\
\hline Gaspésie & $550 \$$ & $590 \$$ & $586 \$$ \\
\hline Sherbrooke & $600 \$$ & $776 \$$ & $751 \$$ \\
\hline
\end{tabular}

SOURCE: R.S.I.P. 145-46, pp. 19, 141, 156, 173, 212.

Il existe donc en plusieurs cas des écarts notablles entre les salaires versés aux enseignantes religieuses et ceux octroyés aux laïques. Ces écarts sont plus prononcés dans les villes de Québec et de Montréal. Or il semble que cet écart se soit quelque peu amenuisé dans la décennie suivante. En effet, en 1955, le Surintendant de l'instruction publique rapporte que le salaire moyen des religieuses enseignantes, pour tout le Québec, est de $1120 \$$, celui des laïques s'élevant à $1630 \${ }^{52}$. Ces

\footnotetext{
${ }^{51}$ Maryse Thivierge, «La syndicalisation des institutrices catholiques 1900-1959», Maîtresses de maison, pp. 181-187.

${ }^{52}$ R.S.I.P., 1955-56, p. 67.
} 
données évidemment ne concernent que les écoles sous contrôle, c'està-dire publiques. Elles permettent d'entrevoir que la hausse des salaires des enseignants laïcs provoque un effet d'entraînement sur la rémunération des enseignantes religieuses. Il s'avérait de plus en plus rentable, pour les congrégations, de développer leur enseignement au secteur public. Les contrats signés avec les commissions scolaires leur permettaient d'assumer les lourdes responsabilités qu'elles s'étaient imposées pour l'enseignement post-primaire offert aux filles. Car l'école obligatoire a entraîné la gratuité de l'enseignement ${ }^{53}$. Les écoles se sont multipliées ${ }^{54}$, et le nombre d'écoles dirigées par les religieuses augmente en flèche. Les écoles publiques se remplissent d'une masse de jeunes dorénavant obligés de fréquenter l'école.

Mais les congrégations religieuses doivent continuer de soutenir seules les institutions indépendantes dispensant le cours de LettresSciences, des cours avancés de musique ou d'enseignement ménager ainsi que le second cycle du cours classique ${ }^{55}$. Or, une faible minorité de jeunes filles fréquentent ces institutions et le nombre de graduées est bien souvent dérisoire. L'exemple des collèges classiques féminins est à cet égard sans doute le plus frappant. Privés de subventions, ces établissements ne comptent que sur les frais d'inscription, de scolarité et de pension pour fonctionner ${ }^{56}$. On peut dès lors se poser la question: les fonds ainsi fournis par les étudiantes des collèges classiques étaient-ils suffisants pour pourvoir entièrement aux coûts de leur formation? Le tableau 14 nous permettra en tout cas de saisir le volume d'étudiantes qui atteignaient l'objectif final des études classiques: le baccalauréat. Le nombre de bachelières est dérisoire dans chacun des collèges étudiés, exception faite du Collège Marguerite-Bourgeoys. Non seulement le nombre de bachelières est-il très faible, mais en plus, le phénomène bien connu de l'entonnoir est saisissant pour toutes les institutions: la persévérance scolaire est réduite. Or ces cours d'enseignement supérieur, qu'ils portent sur les études musicales avancées, sur

\footnotetext{
${ }^{53}$ Gérard Filteau, Organisation scolaire de la province de Québec, Montréal, C.P.P., 1954, pp. 100-1.

${ }^{54}$ Ruby Heap, Les Soeurs de la Charité de Québec, GREF, 1983, pp. 94-5. Toutes nos autres recherches confirment cette affirmation.

${ }^{55}$ La signification et les besoins de l'enseignement classique pour jeunes filles. Mémoire des collèges classiques de jeunes filles du Québec à la Commission royale d'enquête sur les problèmes constitutionnels, 1954.

${ }^{56}$ Les frais sont de $350 \$$ à $600 \$$ dans les collèges classiques contre $250 \$$ à l'école normale. Ibidem, p. 76. Par ailleurs, $14 \%$ des collégiennes reçoivent des bourses dont 75\% de la valeur globale est fournie par les collèges eux-mêmes tandis que $73 \%$ des normaliennes reçoivent des bourses de l'Aide à la jeunesse en plus de prêts et $95 \%$ des étudiantes des instituts familiaux reçoivent des bourses de diverses sources, Ibidem, pp. 108-9.
} 
l'enseignement classique ou la formation reçue dans les instituts de pédagogie familiale, voire le simple cours Lettres-Sciences, exigent tous un personnel nombreux, un équipement varié et dispendieux ainsi que des locaux appropriés dont l'aménagement requiert des investissements quelquefois importants. Ce personnel souvent surchargé ne reçoit aucun salaire. Le ratio professeur-élève est nécessairement très faible ${ }^{57}$. Les investissements en matériel didactique (par exemple: équipement de laboratoires de physique, chimie, biologie, bibliothèque) sont disproportionnés par rapport au volume de la clientèle étudiante.

TABLEAU 14. Nombre moyen de bachelières de quelques collèges classiques féminins (moyenne quinquennale)

\begin{tabular}{|l|c|c|c|c|c|c|c|c|c|}
\hline & 1 & 2 & 3 & 4 & 5 & 6 & 7 & 8 & 9 \\
\hline $1911-1915$ & 2.8 & - & - & - & - & - & - & - & - \\
\hline $1928-1932$ & 14.8 & 2.6 & - & - & - & - & - & - & - \\
\hline $1933-1937$ & 23.8 & 2.2 & 4.6 & - & 3.5 & 0 & - & - & - \\
\hline $1938-1942$ & 23.2 & 4 & 6.6 & - & 8.4 & 0 & 1.5 & 3.6 & - \\
\hline $1943-1947$ & 21 & 8.6 & 6.4 & - & 6.8 & 1.4 & 1 & 5.6 & - \\
\hline $1948-1952$ & 19.8 & 12.8 & 6 & 5.6 & $?$ & 2.6 & 2.8 & 7.4 & 3.7 \\
\hline $1953-1957$ & 30.6 & 9 & 9.8 & 5.3 & $?$ & 4.5 & 3.6 & 8.4 & $?$ \\
\hline
\end{tabular}

SOURCES:

1) Lucienne Plante, L'enseignement classique à la Congrégation Notre-Dame, thèse de Ph. D., Laval, 1972 (Collège Marguerite Bourgeoys).

2) Collège Jésus-Marie de Sillery, «Bachelières finissantes 1928-1969", document dactylographié (5.0).

3) Michèle Jean, Le Collège Marie-Anne, thèse de M.A., Montréal, 1975.

4) Lise Théberge, Le Collège du Bon Pasteur de Chicoutimi, thèse de M.A., UQC, 1982.

5) M.-Paule Maloin, L'enseignement chez les Soeurs des Saints-Noms-de-Jésus-et-de-Marie, GREF, 1983, (Collège Jésus-Marie d'Outremont).

6) Johanne Daigle, L'éducation des filles au couvent des Ursulines de Trois-Rivières 1840-1950, GREF, 1983.

7) Antonine Gagnon, Le collège classique Notre-Dame-de-l'Assomption de Nicolet, thèse de M.A., Laval, 1972.

8) Lucienne Plante, L'enseignement classique... (Collège de Bellevue).

9) Marielle Langlois, L'enseignement chez les Filles du Sacré-Coeur-de-Jésus, GREF, 1983.

${ }^{57} \mathrm{Au}$ Collège Marguerite d'Youville de Hull, on compte 6 religieuses pour 61 élèves en 1955-56; 8 religieuses pour 82 élèves en 1958-59. Voir Andrée Dufour, Les Soeurs Grises de la Croix d'Ottawa et l'éducation des jeunes filles dans l'Outaouais québécois 1901-1968, GREF, 1982, pp. 52 et 69. 
Force nous est de conclure que ce qui était vrai à la fin du $\mathrm{XIX}^{\mathrm{e}}$ siècle - alors que les congrégations religieuses féminines assuraient leur survie grâce à leur réseau privé d'enseignement - ne l'est plus dès 1940. Dorénavant, la survie des congrégations religieuses, sans en être dépendante, peut s'appuyer, en partie, sur le réseau public d'enseignement. Il devient possible aux congrégations de ré-investir une partie des revenus tirés de l'enseignement au secteur public dans les écoles supérieures privées destinées aux filles. Ce que les pouvoirs publics se refusaient à faire, développer un enseignement de qualité pour les filles, les congrégations religieuses enseignantes de femmes l'ont réalisé. Lorsque l'État québécois prendra à sa charge toutes ces responsabilités, les congrégations religieuses seront poliment (?) remerciées.

\section{$* * *$}

L'accès des femmes à l'éducation secondaire, puis aux études universitaires a été rattaché à l'émergence des premières revendications féministes. Le phénomène est très net dans les pays anglo-saxons et il a joué également en France, bien que de manière très différente. Or il semble bien qu'au Québec, l'accès aux études supérieures ait été dû en majeure partie aux congrégations enseignantes ${ }^{58}$. Pour remarquable qu'il soit, cet effort n'en dissimule pas moins quelques contradictions. Nous ne ferons que les énumérer car leur discussion nous entraînerait trop loin.

Tout d'abord, on discerne dans chaque congrégation une habitude très nette de distinguer soigneusement les deux clientèles auxquelles s'adressent les religieuses. Au XIX ${ }^{\mathfrak{e}}$ siècle, on parle couramment de "pauvres" et au $\mathrm{XX}^{\mathrm{e}}$ siècle, les règlements empêchent les élèves de chaque secteur de se rencontrer ou de participer à des activités communes. Mieux, certaines maisons exigent l'internat pour l'accès aux scolarités plus longues. Un dossier considérable pourrait être constitué ici: les religieuses offrent une éducation supérieure et payante à l'élite de la société pendant qu'elles se dévouent à enseigner à la masse dans des classes surpeuplées: clivage social qu'elles ont endossé, respecté et contribué à maintenir. Elles ont même établi une hiérarchie entre leurs propres maisons, du très noble collège classique à l'humble pensionnat rural où l'on n'offre qu'une scolarité réduite.

\footnotetext{
${ }^{58}$ Marta Danylewycz, «Une nouvelle complicité: féministes et religieuses à Montréal, 1890-1925 " dans Marie Lavigne et Yolande Picard, Travailleurs et féministes, BoréalExpress, 1983, pp. 245-70.
} 
L'examen de la philosophie de l'enseignement qu'elles ont proposée à leurs élèves fait apparaître une seconde contradiction. Le discours officiel proclame l'objectif traditionnel: préparer de meilleures épouses et de meilleures mères de famille. Mais celles qui propagent le message ont le statut de religieuses célibataires, présentent à leurs élèves des modèles de vie professionnelle et exigent auprès des autorités des diplômes utiles qui permettent de gagner sa vie. L'étude de la force d'attraction du modèle qu'elles ont présenté offre des avenues intéressantes qu'il importe d'examiner ${ }^{59}$.

Il existe enfin une troisième contradiction, plus subtile celle-là, relative aux aspirations professionnelles des élèves. Théoriquement, les religieuses préparent leurs élèves à exercer plusieurs occupations; mais en même temps, l'organisation sociale laisse le contrôle de plusieurs de ces occupations aux congrégations elles-mêmes. Combien de femmes au Québec sont entrées en religion pour enseigner la littérature, la philosophie ou la musique? pour exercer les fonctions les plus intéressantes de la profession d'infirmière? Pour exercer efficacement le service social? ou tout simplement pour poursuivre des études? ${ }^{60}$

C'est à ces questions que s'intéresse maintenant le Groupe de recherche en histoire de l'éducation des filles.

\section{Micheline DumonT \\ Marie-Paule MALOUIN \\ Groupe de recherche en histoire de l'éducation des filles}

\footnotetext{
${ }^{59}$ Danielle Juteau-Lee, "Les religieuses du Québec: leur influence sur la vie professionnelle des femmes: 1908-1954", dans Atlantis, vol. 5, no 2 (printemps 1980), pp. 22-3.

${ }^{60}$ Barbara Cooper, In the Spirit: Entrants to a Religious Community of Women in Quebec: 1930-1939, Thèse de maîtrise, Université McGill, 1983.
} 